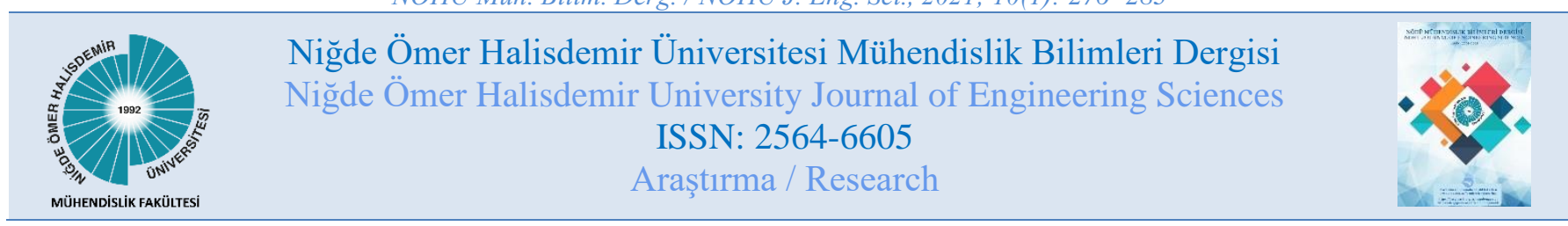

\title{
Gelir getirmeyen su oranı tahmin modelleri
}

\author{
Prediction models for non-revenue water ratio
}

\author{
Burak Kızılöz 1,* (iD), Eyüp Şişman 2,3 (D) \\ ${ }^{I}$ Kocaeli Büyükşehir Belediyesi, ISSU Genel Müdürlüğ̈̈, Çevre Koruma ve Kontrol Daire Başkanlığı, 41200, Kocaeli Türkiye \\ ${ }^{2}$ İstanbul Medipol Üniversitesi, Mühendislik ve Doğa Bilimleri Fakültesi, İnşaat Mühendisliği Bölümü, 34810, İstanbul Türkiye \\ ${ }^{3}$ İstanbul Medipol Üniversitesi, İklim Değişikliği Uygulama ve Araşttrma Merkezi (IKLIMMER), 34810, İstanbul Türkiye)
}

\section{Özet}

Bu araştırmada Gelir Getirmeyen Su Oranı (GGSO) tahminleri, Kocaeli'nin en fazla su kaybı yaşanan altı ilçesinin 2018 ve2019 yıllarına ait iki yıllık verisi dikkate alınarak ve tüketilen su miktarl, sebeke uzunluğu, servis bağlantı uzunluğu, toplam şebeke uzunluğu, şebeke yaşı ve sebeke basıncı ana parametreleri kullanılarak gerçekleştirilmiștir. Model tahminleri iki girdi ve tek çıtılı Yapay Sinir A $\breve{g}$ (YSA) modelleri ve Kriging yöntemi ile gerçekleştirilmiştir. Modellerde toplam şebeke uzunluğu ve iki girdili YSA model kombinasyonlarında ise, servis băglantı uzunluğu ilk kez bu araştırmada model girdisi olarak kullanılmıştır. Yöntemlerin model çıtı performansları $R^{2}$ ve HKOK performans ölçütleri üzerinden değerlendirilmiştir. Sonuç olarak; Kriging yöntemi ile gerçekleştirilen modellerin tahmin performansları YSA yöntemine göre oldukça iyidir. Kriging tekniği ile oluşturulan GGSO tahmin model çıtılarının değerlendirilmesi ve yorumlanmast elde edilen tahmin haritalart sayesinde daha kolay yapllabilirken, kapalı model yapısina sahip olan YSA model sonuçlarında bu durum nitelikli uzmanlık gerektirmektedir.

Anahtar kelimeler: Kriging, Yapay sinir ağı, Gelir getirmeyen su oranı, Su dağıtım şebekesi, Kocaeli

\section{Giriş}

Ülkemizdeki belediyeler ve özel şirketler su, kanalizasyon, yağmursuyu, elektrik ve doğalgaz gibi çok önemli alt yapı hizmetlerine destek sağlamaktadır. Bunlar içerisinde özellikle su dağıtım şebekesi altyapılarına gereken önemin verilmediği, su kayıplarının çok yüksek olmasından bilinmektedir. Bir su dağıtım şebekesi, farklı çaplarda şebeke boruları, çeşitli hacimlerde su depoları, belli güçte pompalar, vanalar, dirsekler, vantuzlar ve tahliye özelliği olan çeşitli bileşenlerden bir araya gelmektedir. Bu bileşenlerin herhangi birisinde ortaya çıkan arızalar, ciddi su kayıplarına sebep olabilmekte, beraberinde su ve hizmet kalitesini de etkilemektedir.

Dünya genelinde yıllık toplam Gelir Getirmeyen $\mathrm{Su}$ (GGS) miktarının yaklaşık 126 milyar $\mathrm{m}^{3}$ olduğu ve bunun ekonomik değerinindi yaklaşık 39 milyar dolar olduğu tahmin edilmektedir [1]. Gelişmiş ülkelerde GGSO \%10 seviyesinin altına düşürülebilirken, gelişmekte olan ülkelerde bu oran \%20-60 aralığındadır [2]. Yüksek GGSO idarelerin bütçelerini olumsuz etkileyip, yeni yatırımların önündeki en büyük engellerden biridir.

$\mathrm{Su}$ dağıtım şebekelerindeki kayıplar sıklıkla American Water Works Association (AWWA) ve International Water Association (IWA) tarafindan önerilen su denge birleşenleri kullanılarak değerlendirilmektedir [3, 4]. Bu araştırma
Abstract

In this study, Non-Revenue Water Rate (NRWR) predictions have been made by taking into account two-year data (2018 and 2019) of Kocaeli and using the main parameters of consumed water amount, network length, service connection length, total network length, network age and network pressure in only six districts with the highest water loss. Model predictions have been made by both Artificial Neural Network (ANN) models with two inputs one output and Kriging method. In this study, the total network length for all model combinations and the service

connection length for ANN combinations with two inputs have been used as a model input for the first time. The model output performances of the above-mentioned methods have been evaluated in accordance with $R^{2}$ and HKOK criteria. In conclusion, it is obvious according to the results that the model prediction performances made by Kriging method are better than the other one (ANN method). On the other hand, while evaluating the NRWR prediction model outputs established by Kriging method is easier through the prediction charts, this requires a specialized skill set for evaluating the ANN results

Keywords: Kriging, Artificial neural network, Non revenue water ratio, Water distribution network, Kocaeli

çalışmasında da IWA tarafından önerilen ve standartlaştırılan GGS değerleri kullanılmıştır. GGS faturalandırılmamış izinli tüketim ile, idari ve fiziki kayıplardan oluşur.

GGS miktarının azaltılması ve kontrol altında tutulabilmesi için yapılan çalıșmalar incelendiğinde, literatürde ülkemizde de bazı araştırmaların olduğu görülmektedir. Kanakoudis ve Muhammetoğlu [5], Antalya ve Kos bölgelerindeki GGS miktarını azaltabilmek için, hidrolik model üzerinde çalışmışlardır. Çalışma sonunda her iki bölgede minimum gece debilerinde azalmalar ortaya çıkmıştır. Malatya su dağıtım şebekesi servis bağlantılarında oluşan sızmaların GGS miktarı üzerindeki etkisi Boztaş vd. [6] tarafından araştırılmıştır. 14 izole alan için, akustik dinleme cihazı ile arızalar tespit edilerek, su kayıpları azaltılmıştır. Tasarruf edilen toplam debi miktarı 148,9 lt/sn'dir. Bu çalışmalarla birlikte literatürde ayrıca, GGS miktarını azaltmak için idari ve fiziki kayıplar üzerine yapılmış ulusal ve uluslararası pek çok araştırma da bulunmaktadır [7-14].

GGSO tahminine yönelik literatür incelemesi yapıldığında ise, daha az sayıda araştırmanın olduğu görülmüştür. Bu çalışmalardan birinde, Jang ve Choi [15] tarafından gerçekleştirilen bir araştırmada, Yapay Sinir Ağ (YSA) ve Çoklu Regresrasyon Analiz (ÇRA) yöntemleri kullanılarak GGSO tahmin modelleri geliştirilmiştir. YSA

\footnotetext{
* Sorumlu yazar / Corresponding author, e-posta / e-mail: bkiziloz@isu.gov.tr (B. Kızılöz)

Geliş / Recieved: 02.09.2020 Kabul/ Accepted: 10.12.2020 Yayımlanma / Published: 15.01.2021

doi: $10.28948 /$ ngmuh.789694
} 
model sonuç performansları, ÇRA'ya göre daha yüksek olarak belirlenmiştir (YSA için $\mathrm{R}^{2}=0.63$ ve ÇRA için $\mathrm{R}^{2}=0.19$ 'dur). Jang ve Choi [16] tarafindan yapılan bir diğer araştırmada bu kez orijinal ve standartlaştırılmış verilerin kullanıldı̆̆ 1 farklı nöron sayılarında YSA modelleri oluşturulmuştur. Çalışma sonunda performansı en iyi model için $\mathrm{R}^{2}$ değeri, 20 nöron için, 0.397 olarak belirlenmiştir. Şişman ve Kızılöz [17] Kocaeli'nin tüm ilçelerinin on iki izole bölgesinin 2018 y1lı on iki aylık toplam 144 adet verisini kullanarak, YSA ve Kriging yöntemleri ile GGSO' $\mathrm{n} 1$ tahmin etmişlerdir. Model girdileri olarak, su dağıtım sistemine giren su miktarı, şebeke uzunluğu, arıza sayısı, servis bağlantı sayısı, su sayacı sayısı, düğ̈̈m noktası sayısı, servis bağlantı uzunluğu, içme suyu deposu hacmi, ortalama şebeke basıncı, boru çapları ve boru yaşları seçilmiştir. Sıralanan her bir değişkenin GGSO üzerindeki etkisini ortaya koyabilmek için, öncelikle YSA ile tek girdili modeller oluşturulmuştur. Sonrasında sırayla girdi sayıları artırılarak iki, üç ve dört girdili YSA modelleri geliştirilmiştir. Tüm bu modellerde veri setinin \%55'i eğitim, \%35'i doğrulama ve \%10'uda test şeklinde bölünmüştür. En sonunda benzer değişkenler kullanılarak, Kriging yöntemi ile iki girdili ve tek çıktılı tahmin model haritaları hazırlanmıştır. Araştırmalarda en yüksek model performansı Kriging yöntemi ile elde edilmiş olup, $\mathrm{R}^{2}$ değeri 0.95 'dir. En iyi model sonucunun elde edildiği kombinasyonda girdi değişkenlerinin, sisteme giren su miktarı/düğüm noktası sayısı ve ortalama şebeke basıncı oldukları görülmüştür. Şişman ve Kızılöz [17] bu araştırmada şebeke basıncı ve boru yaşlarını, GGSO tahmin modelinde, ilk kez girdi olarak kullanmışlardır.

$\mathrm{Bu}$ araştırma çalışması, Şişman ve Kızılöz’ün [17] makale çalışmasından esinlenilerek ve tahmin modellerinde önceki araştırmadan ayıran belli değişiklikler ile, Kocaeli' nde en fazla su kaybı yaşanan altı ilçe için, 2018 (72 adet) ile birlikte 2019 (72 adet) yılları verileri de kullanılarak, oluşturulmuştur. Ayrıca her iki tahmin yönteminde tercih edilen toplam şebeke uzunluğu ve bunun yanında iki girdili YSA model kombinasyonlarındaki servis bağlantı uzunlukları, ilk kez bu araştırmada model girdisi olarak düşünülmüş̧ür.

\section{Materyal ve metot}

$\mathrm{Bu}$ araştırma makalesinde GGSO'nun modellenmesinde Kriging ve YSA yöntemleri kullanılmıştır. Kriging modellerinde Surfer program1, YSA modellerinde ise MATLAB programı tercih edilmiştir. Modeller iki girdi ve tek çıktılı yapıya sahiptir. Model girdi değişkenleri tüketilen su miktarı (TSM), şebeke uzunluğu (ŞU), servis bağlantı uzunluğu (SBU), toplam şebeke uzunluğu (TŞU), şebeke basıncı (ŞB) ve şebeke yaşı (ŞY) değişkenleri arasından seçilmiş olup, çıktı GGSO değişkenidir. YSA ve Kriging yöntemlerinde benzer girdi kombinasyonları üzerinden model sonuçları ve performansları karşılaştırılmıştır. Oluşturulan modellerin performans değerlendirmesi korelasyon katsayısı $\left(\mathrm{R}^{2}\right)$ ve hataların karesinin ortalamasının kareköküne (HKOK) göre değerlendirilmiştir.

\section{1 Çalışma alanı ve veriler}

Araştırma için Kocaeli Su ve Kanalizasyon İdaresi Genel Müdürlüğü'nün (ISU) hizmet sahasında olan on iki ilçesi arasından en yüksek GGSO'na sahip altı ilçesi (Kandıra, Kartepe, Körfez, Karamürsel, Gölcük ve Derince) seçilmiştir. Belirlenen altı ilçenin 2019 yılı toplam nüfusu 708.596 kişi olup, toplam şebeke uzunluğu $5077 \mathrm{~km}$ ve tüketilen su miktarı $210.990 .587 \mathrm{~m}^{3}$ 'tür. Bu ilçelerin toplam abone sayısı ise 315.181'dir [18]. Bu altı ilçenin 2018-2019 yılları aylık GGSO miktarları incelendiğinde, en yüksek GGSO Kartepe'de, en düşük ise Kandıra'dadır. Seçilen altı ilçenin su dağıtım sistemine ilişkin istatistiki bilgilere aşağıdaki Tablo 1'de bu araştırma çalışması başlığı altında yer verilmiştir. Ayrıca Tablo 1'de bu araştırmanın model girdi ve çıktılarına ilişkin istatistiki bilgiler yanında, Şişman ve Kızılöz’ün [17] çalışmasında kullandığı veriler karşılaştırma amaçlı verilmiştir. Tablo 1'de yer alan toplam şebeke uzunluğu bu çalışmada, tüm modeller için ilk defa model girdisi olarak kullanılmıştır.

\subsection{Yapay sinir ăglart}

YSA modelleri için sıklıkla kullanılan İleri Beslemeli (IB) Geri Yayılımlı (GY) (feed-forward back propogation) ağ yapısından faydalanılmıştır. Klasik örnek bir ağ mimarisi, Şekil 1'de görüldüğü şekilde girdiler, gizli katman ve çıktılardan oluşmaktadır.

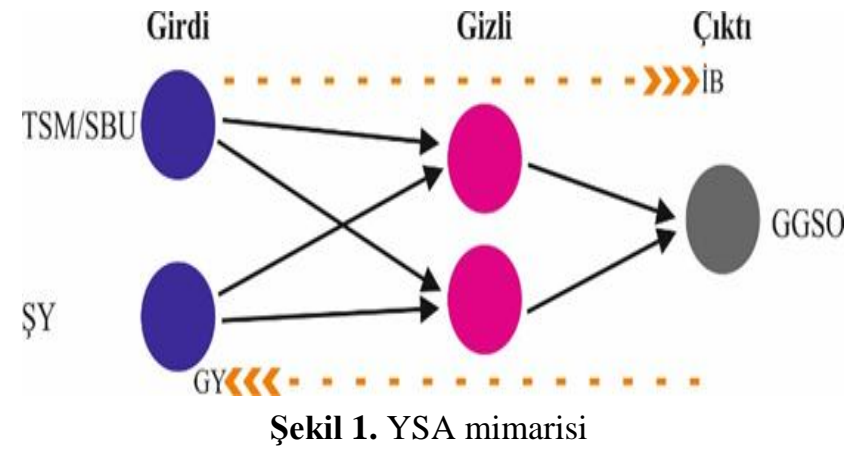

Model sürecinde ağ eğitimi için, pek çok araştırmada tercih edilen Geri Yayılımlı (GY) Levenberg-Marquardt algoritması kullanılmıştır [17 19]. Model çıktısı ve beklenen model sonucu arasındaki farklar, bu algoritma yardımıyla hata değerinin en küçüklenmesi yönünde, ağ sürekli olarak geriye doğru tekrar tekrar çalıştırılmıştır. Model veri setinde, 2018 ve 2019 yıllarında belirlenen altı ilçede aylık hesaplanan, toplam 144 adet veri bulunmaktadır. Bu veri setinin \%65'i (93 adet) eğitim, \%20'si (29 adet) doğrulama ve kalan \%15'i (22 adet) test için, rastgele şekilde bölünmüştür. $\mathrm{Bu}$ şekilde veri setinin kullanımı için de Şişman ve Kızılöz'ün [17] model çalışmasından farklı bir dağılım tercih edilmiştir. Modelin gizli katmanında sigmoid ve çıktı katmanında ise lineer aktivasyon fonksiyonu ile işlemler gerçekleştirilmiştir. Gizli katmandaki nöron sayısına deneme yanılma ile karar verilmiştir. 
Tablo 1. Model girdi ve çıktıları

\begin{tabular}{|c|c|c|c|c|c|c|}
\hline \multirow{2}{*}{ Girdi ve Çıktı } & \multirow{2}{*}{ Kisaltma } & \multicolumn{2}{|c|}{$\mathrm{Bu}$ araştırma çalışması } & \multicolumn{2}{|c|}{ Şişman ve Kızılöz [17] } & \multirow{2}{*}{ Birim } \\
\hline & & Minimum & Maksimum & Minimum & Maksimum & \\
\hline Tüketilen Su Miktarı & TSM & 315.445 & 1.461 .737 & 315.445 & 2.844 .526 & $\mathrm{~m}^{3}$ \\
\hline Şebeke Uzunluğu & ŞU & 429 & 1631 & 306 & 1600 & $\mathrm{~km}$ \\
\hline Servis Bağlantı Uzunluğu & SBU & 131 & 393 & 128 & 527 & $\mathrm{~km}$ \\
\hline Toplam Şebeke Uzunluğu & TŞU & 1738 & 207.808 & - & - & $\mathrm{km}$ \\
\hline Şebeke Basıncı & ŞB & 43 & 60 & 43 & 64 & $\mathrm{~m}$ \\
\hline Şebeke Yaşı & ŞY & 14 & 31 & 8 & 30 & y1l \\
\hline Gelir Getirmeyen Su Oranı & GGSO & 0.21 & 0.54 & 0.13 & 0.54 & - \\
\hline
\end{tabular}

\section{$2.3 \quad$ Kriging}

Kriging metodolojisinde, eldeki veriler kullanılarak üç boyutlu yüzey modelleri oluşturulmakta ve bu modeller yardımıyla girdilere karşılık model çıktı tahminlerinde bulunulmaktadır. Model tahminleri için ölçüm değerlerine karşılık gelen çıktılar enterpolasyon tekniği ile belirlenmiştir. Kriging'de en önemli etken ağırlıkların belirlenmesidir. Model ağırlıklarına variogram fonksiyonu yardımıyla karar verilmiştir. Model için kullanılan verilerin ağırlıklı ortalaması ile çıktılar tahmin edilmektedir. Kriging yöntemi genel eşitliği aşağıda Denklem (1) ile verilmiştir [20].

$$
Z\left(x_{0}\right)=\sum_{i}^{N} W_{i} Z\left(x_{i}\right)
$$

\subsection{Model performans ölçütleri}

Araştırmada kullanılan modellerin tahmin performansları aşağıda verilen (2) ve (3) numaralı denklemler yardımıyla değerlendirilmiştir.

$$
\begin{gathered}
R^{2}=\frac{\left[\sum_{i=1}^{n}\left(x_{i}-\bar{x}\right)\left(y_{i}-\bar{y}\right)\right]^{2}}{\sum_{i=1}^{n}\left(x_{i}-\bar{x}\right)^{2} \sum_{i=1}^{n}\left(y_{i}-\bar{y}\right)^{2}} \\
H K O K=\sqrt{\frac{\sum_{i=1}^{n}\left(x_{i}-y_{i}\right)^{2}}{n}}
\end{gathered}
$$

\section{Bulgular ve tartışmalar}

\subsection{Yapay sinir ăgları (YSA)}

GGSO’nun tahmin edilmesinde öncelikle iki girdili ve tek çıktılı YSA modelleri kullanılmıştır. Modellerde veriler eğitim, doğrulama ve test için MATLAB programı yardımıyla rastgele şekilde üç parçaya ayrılmıştır. Gizli katmandaki nöron sayısı model performansı göz önüne alınarak dört olarak belirlenmiştir. Altı farklı model kombinasyonu için elde edilen $\mathrm{R}^{2}$ ve HKOK değerleri Tablo 2'de verilmiştir. Geliştirilen YSA modelleri için $\mathrm{R}^{2}$ değerleri 0.366 ile 0.397 aralığında değişirken, HKOK değerleri 0.051-0.052'dir. GGSO hesap değerleri ile YSA tahmin modellerinin arasındaki benzerlik ve farklar Şekil 2 üzerinden değerlendirilebilir. Şekil 2'de yer alan grafiklere ve $\mathrm{R}^{2}$ 'ye göre en iyi tahmin YSA.M.1 modeli ile ortaya konulmuş olup, $\mathrm{R}^{2}$ değeri 0.397 ve HKOK değeri 0.051 'dir. $\mathrm{Bu}$ grafiklerde kırmızı doğrunun üst kısmında kalan saçılımlar hesap değerlerine göre tahminlerin yüksek olduğunu, doğrunun alt kısmındaki saçılımlar ise tahminlerin hesap değerlerine göre küçük kaldığını gösterir. Buna göre genel olarak geliştirilen YSA modellerinin performansları ve tahmin doğrulukları iyi zayıftır.

Tablo 2 Tahmin modelleri performans sonuçları

\begin{tabular}{cccc|ccc}
\hline & & \multicolumn{3}{c|}{ Kriging } & \multicolumn{3}{c}{ YSA } \\
\cline { 2 - 7 } Girdiler & Model No & $\mathrm{R}^{2}$ & HKOK & Model No & $\mathrm{R}^{2}$ & HKOK \\
\hline TSM/SBU-ŞY & K.M.1 & 0.886 & 0.022 & YSA.M.1 & 0.397 & 0.051 \\
TSM/TŞU-ŞY & K.M.2 & 0.836 & 0.027 & YSA.M.2 & 0.366 & 0.052 \\
& & & & & & \\
TSM/ŞU-ŞY & K.M.3 & 0.811 & 0.029 & YSA.M.3 & 0.374 & 0.052 \\
& & & & & & \\
TSM/SBU-ŞB & K.M.4 & 0.799 & 0.029 & YSA.M.4 & 0.386 & 0.051 \\
& & & & & & \\
TSM/TŞU-ŞB & K.M.5 & 0.743 & 0.033 & YSA.M.5 & 0.384 & 0.051 \\
TSM/ŞU-ŞB & K.M.6 & 0.736 & 0.033 & YSA.M.6 & 0.385 & 0.051 \\
\hline
\end{tabular}




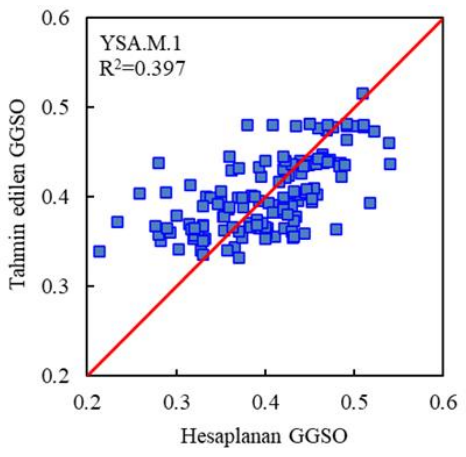

(a)

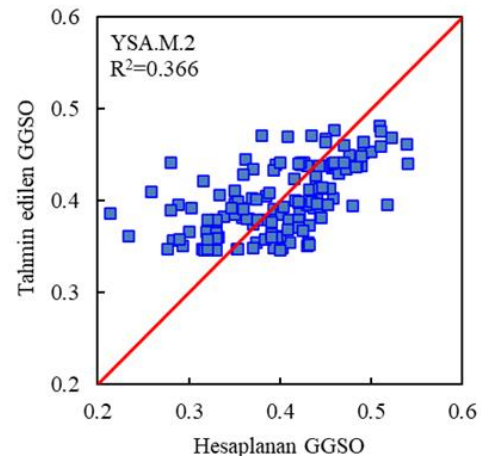

(b)

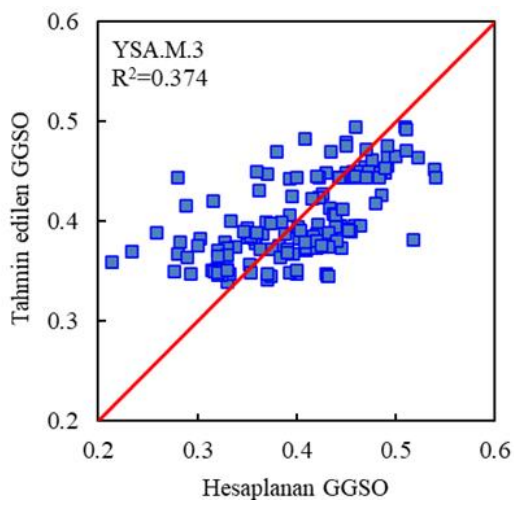

(c)

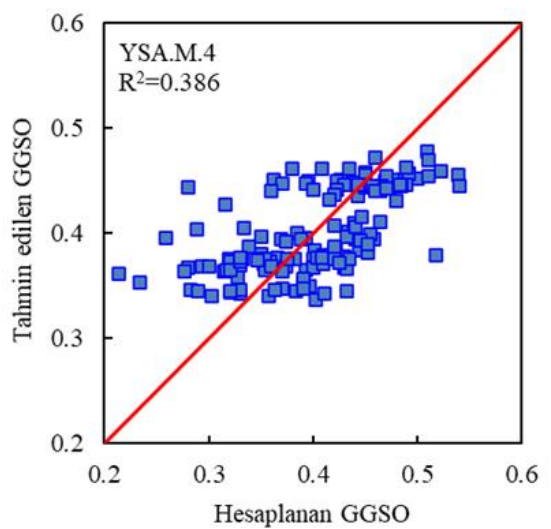

(d)
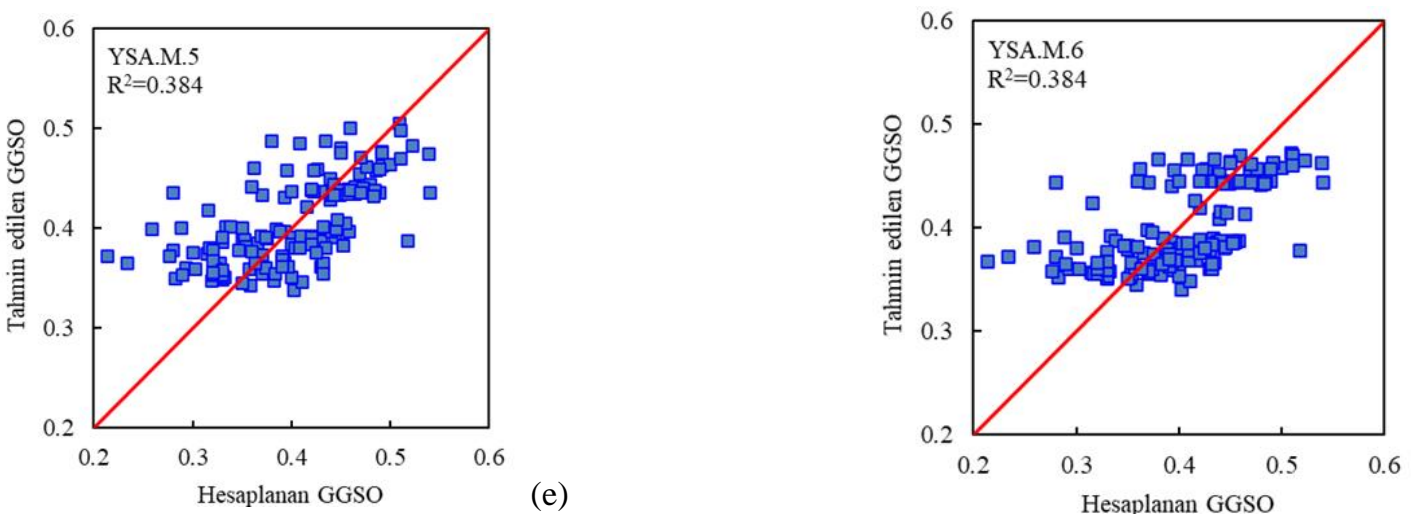

(f)

Şekil. 2. GGSO hesap değerleri ile YSA tahmin model sonuçları kıyaslama grafikleri

\subsection{Kriging}

YSA modellerinden sonra daha iyi GGSO tahminleri için Kriging metedolojisi kullanılarak bu modellerin performansları belirlenmiştir. Bu amaçla, YSA modellerinde kullanılan girdi eşleşmeleri için, öncelikle Surfer programı yardımıyla Kriging metodolojisi kullanılarak GGSO model tahmin haritaları hazırlanmıştır. Model haritalarındaki X, Y koordinatları model girdilerini ve $\mathrm{Z}$ koordinatı ise model çıktısını verir. Tüm modeller, nokta Kriging ve lineer yarıvariogram kullanılarak geliştirilmiştir. Kriging ve YSA tahmin modelleri performans sonuçları karşılaştırmalı şekilde yukarıda Tablo 2'de sunulmuştur.

GGSO tahmininde Kriging modellerinin YSA'ya göre model performansları ve doğrulukları Tablo 2'den görüldüğü gibi çok daha yüksektir. Kriging metodolojisi ile GGSO tahmininde K.M.1 no'lu model için $\mathrm{R}^{2}$ değeri 0.886 iken, aynı kombinasyonun YSA ile çözüm sonucunda elde edilen $\mathrm{R}^{2}$ değeri 0.379 'dur. Kriging yöntemi model performansının YSA'ya göre oldukça iyi olduğu $\mathrm{R}^{2}$ ve HKOK değerlerinden görülmektedir. Tablo 2'de verilen diğer beș model kombinasyonu için de Kriging modellerinin YSA'ya göre oldukça üstün oldukları görülmüştür. Kriging modellerinin $\mathrm{R}^{2}$ değerleri $0.74-0.89$ aralığında olup, 0.370.40 aralığında değişen YSA modellerine göre oldukça yüksektir. Kriging yönteminde belirlenen kombinasyonlar içerisinde en düşük model doğruluğu TSM/ŞU-BŞ (K.M.6 modeli) ye aittir. Diğer taraftan Kriging tahmin haritaları sayesinde uzmanlar şekil bilgisinin sunduğu avantajı da kullanarak model çıktılarını daha kolay yorumlayabilir. Bu araştırma çalışmasındaki GGSO tahmin model performans sonuçları ile Jang ve Choi [15-16] tarafindan geliştirilen model performans sonuçları karşılaştırılırsa, bu araştırmada daha az girdi ile çok daha belirgin şekilde yüksek model doğrulukları elde edilmiştir. Şekil 3'de altı model kombinasyonu için hazırlanan Kriging tahmin haritaları yer 
almakta olup, bunlarla birlikte GGSO hesap ve YSA-Kriging model tahmin sonuçları saçılımları kıyaslama için Kriging grafiklerinin să tarafinda verilmiştir. Grafiklerde siyah daireler Kriging modellerine, mavi kareler ise YSA modellerine aittir. GGSO hesaplar1 yatay eksende, model tahminleri düşey eksende gösterilerek modellerin doğrulukları (performansları) değerlendirilmiştir. Noktaların 1:1 eğimli kırmızı doğru etrafındaki saçılım varyanslarına bakılarak en iyi modellerin Kriging ile elde edildiği görülebilir. Altı model kombinasyonu içinde hesap ve tahminlerin birbirine yakınlıkları modelden modele farklılık göstermektedir. ŞY değişkeni ile kurulan modellerin doğruluklarının ŞB'na göre çok daha iyi olduğu Şekil 3b, 3d ve $3 \mathrm{f}$ grafikleri ile Şekil $3 \mathrm{~h}, 3 \mathrm{i}$ ve $3 \mathrm{k}$ grafiklerinin mukayesesinden çıkarılabilir.

Bu araştırma ile Şişman ve Kızılöz'ün [17] ilk araştırma sonuçları karşılaştırmalı olarak Tablo 3'de sunulmuştur. Her iki araştırmada da tahmin modellerinin oluşturulmasında toplam 144 adet veri kullanılmıştır. Ancak Şişman ve Kızılöz [17] tarafından ilk kez yapılan araştırmada Kocaeli sınırları içindeki on iki ilçenin 2018 yılı aylık verilerini kullanarak GGSO modellerini oluştururken, bu çalışma da tüm ilçeler içerinde su kayıp oranı en yüksek olan altı ilçenin 2018 ve 2019 yılları aylık verileri kullanılmıştır. Dolayısıyla bu çalışmada elde edilen model tahminlerinin ve performanslarının daha düşük olması, en yüksek GGSO oranlı ilçelerin seçilmesine de bağlı olarak, yazarlar tarafından doğal olarak değerlendirilmiştir. Ayrıca sunulan çalışmada verilen kombinasyonlar için de şebeke ve servis

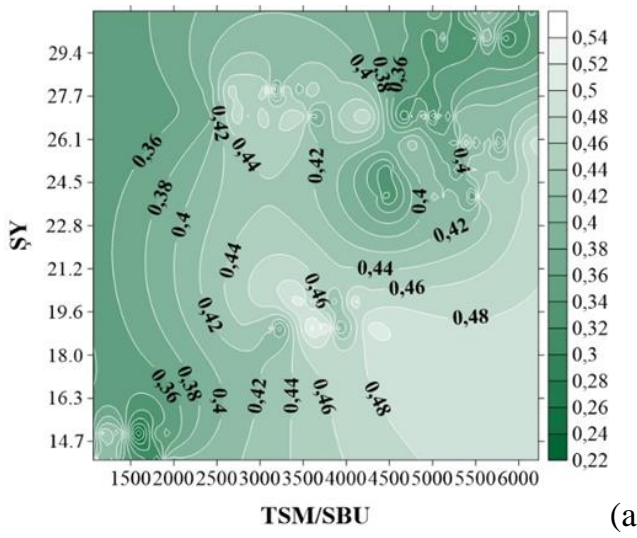

(a)

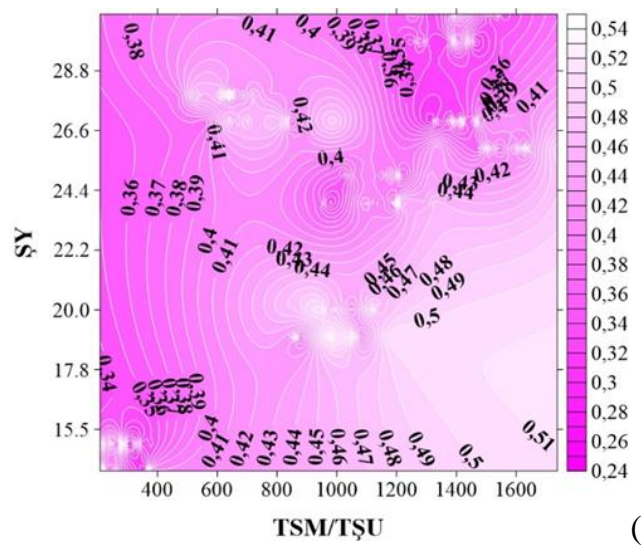

(c) bağlantı uzunluğu etkisini bir arada içeren toplam şebeke uzunluğu ilk kez bu araştırmada model girdisi olarak seçilmiştir.

Tablo 3'ü incelediğimizde, model performansları açısından, Şişman ve Kızılöz'ün [17] ilk çalışması ile arasındaki farklılıklar dikkat çekicidir. Bunun sebebi bu araştırmada performansı en düşük ve su kaybı en yüksek ilçelerin verileri kullanılarak tahmin modellerinin geliştirilmesidir. $\mathrm{Bu}$ durumda geliştirilen model performanslarının, belirlenen iki gösterge üzerinden, gerilediği görülmektedir. GGSO yüksek ilçelerde kayıplarla birlikte yıl içerisindeki değişkenlikte fazladır. Bunun da tahmin modellerinin performansları üzerinde dezavantajlı bir durum oluşturduğu düşünülmektedir. Bir su dağıtım şebekesinde yüksek su kayıp değerleri söz konusu ise, düşük kayıp değerlerine göre model sonuçlarının ve performanslarının da bununla orantılı kötü yönde etkileneceği beklenen bir durum olup, araştırmada bunu desteklemektedir. Ancak Kriging model performansları, bu yüksek GGSO verilerine rağmen, oldukça iyidir. YSA model performansları bu araştırma sonuçları açısından geliştirilen modellerin kullanılmaması gerektiğini göstermektedir. Sonuç olarak şebekelerde su kayıplarının düşürülmesi ve bu yönde adımlar atılması, su kayıplarının ve şebekelerin yönetimleri için geliştirilen karar destek tahmin model doğruluklarını da etkileyecek ve su kayıplarının daha da azaltılması için doğru kararlar alınabilmesine yardımcı olacaktır.

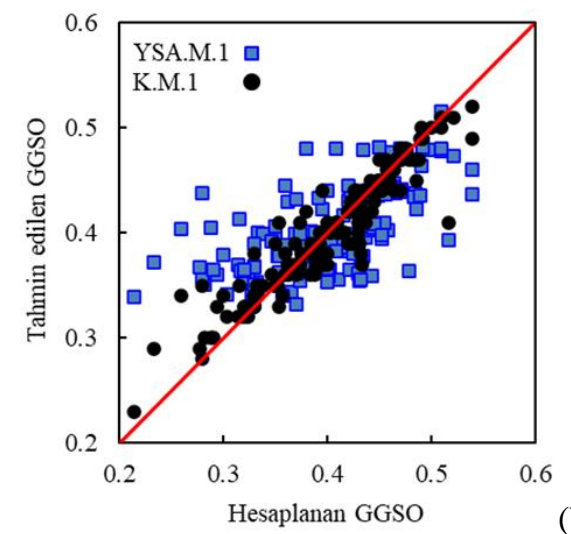

(b)

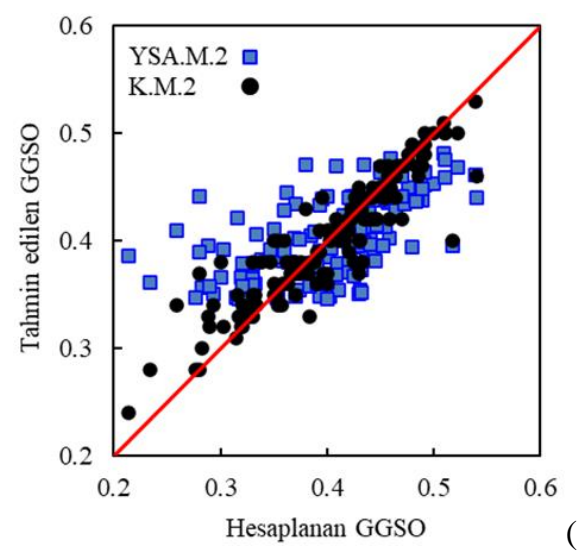

(d)

Şekil. 3. Kriging model tahmin haritaları ve model sonuçları kıyaslama grafikleri 

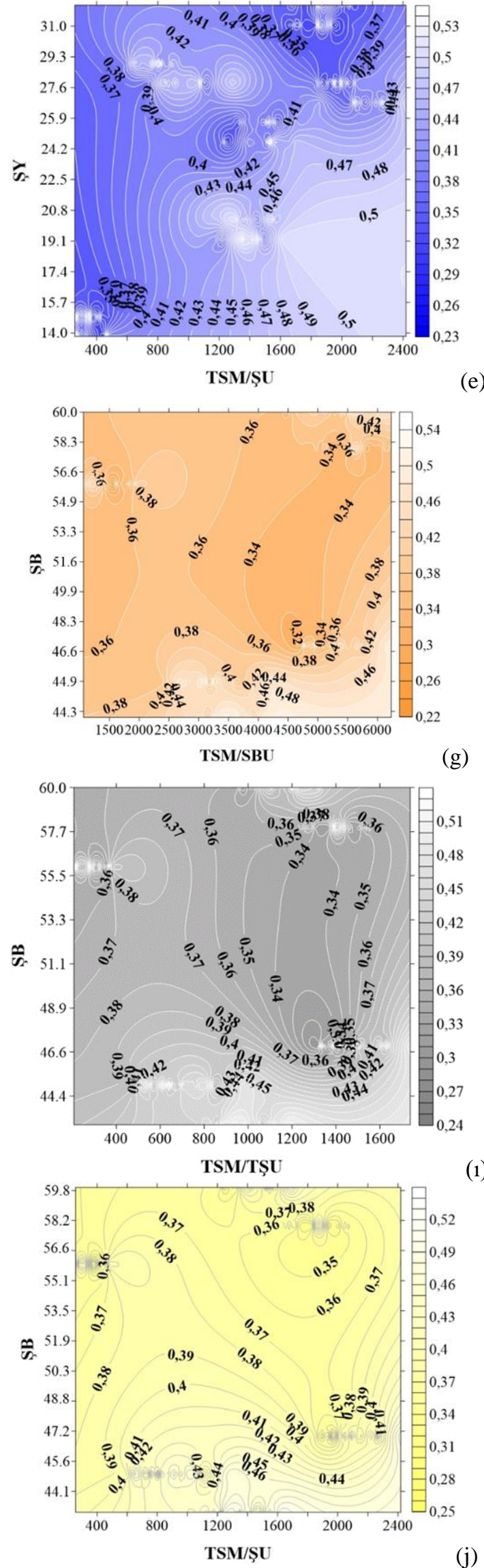
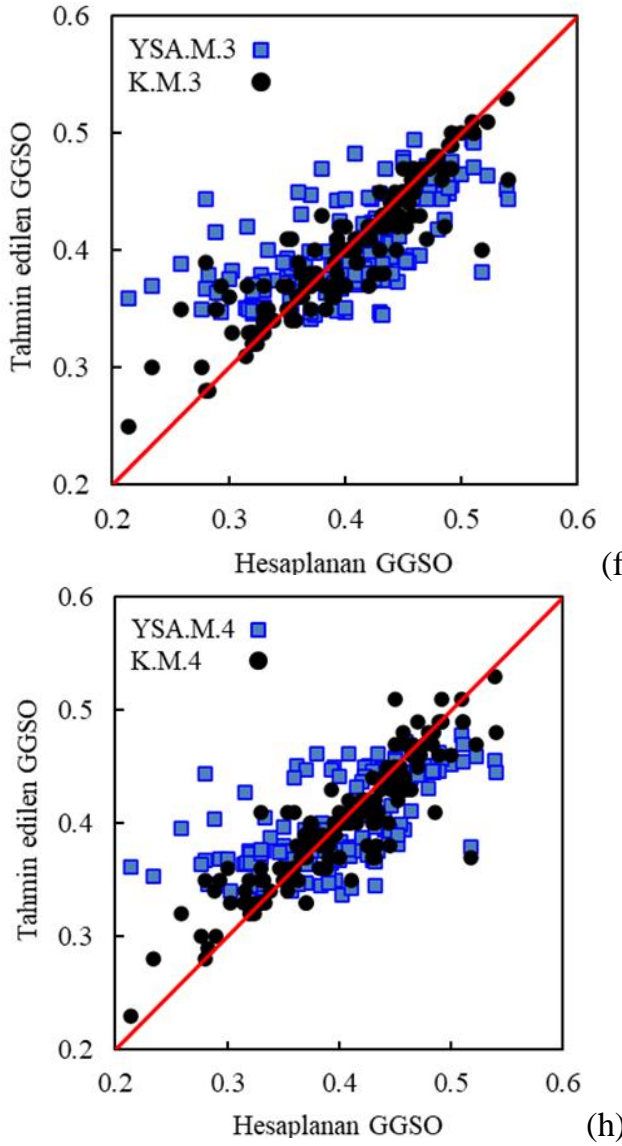

(f)
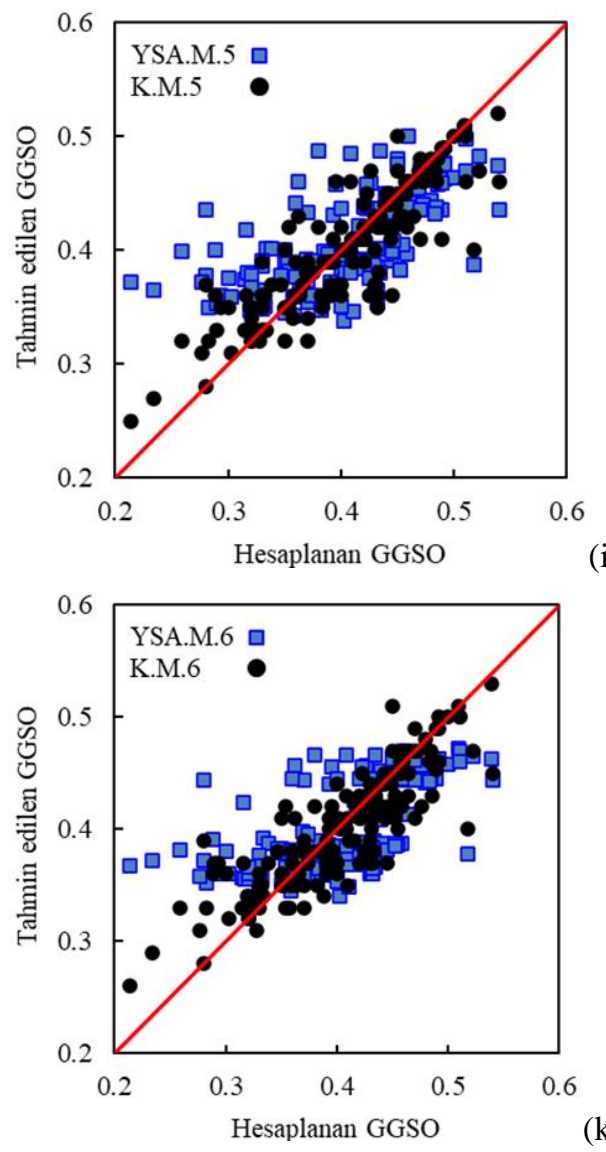

(k)

Şekil. 3 (devam). Kriging model tahmin haritaları ve model sonuçları kıyaslama grafikleri 
Tablo 3 GGSO model sonuçlarının karşılaştırılması

\begin{tabular}{|c|c|c|c|c|c|c|c|c|}
\hline \multirow{3}{*}{ Girdiler } & \multicolumn{4}{|c|}{ Kriging } & \multicolumn{4}{|c|}{ YSA } \\
\hline & \multicolumn{2}{|c|}{ Bu çalışma } & \multicolumn{2}{|c|}{$\begin{array}{l}\text { Şişman ve } \\
\text { Kızlöz [17] }\end{array}$} & \multicolumn{2}{|c|}{ Bu çalışma } & \multicolumn{2}{|c|}{$\begin{array}{c}\text { Şişman ve } \\
\text { Kızılöz [17] }\end{array}$} \\
\hline & $\mathrm{R}^{2}$ & HKOK & $\mathrm{R}^{2}$ & HKOK & $\mathrm{R}^{2}$ & HKOK & $\mathrm{R}^{2}$ & HKOK \\
\hline TSM/SBU-ȘY & 0.89 & 0.022 & 0.93 & 0.0006 & 0.397 & 0.051 & - & - \\
\hline TSM/TŞU-ŞY & 0.84 & 0.027 & - & - & 0.366 & 0.052 & - & - \\
\hline TSM/ŞU-ŞY & 0.81 & 0.029 & 0.90 & 0.0008 & 0.374 & 0.052 & - & - \\
\hline TSM/SBU-ȘB & 0.80 & 0.029 & 0.93 & 0.0006 & 0.386 & 0.051 & - & - \\
\hline TSM/TŞU-ŞB & 0.74 & 0.033 & - & - & 0.384 & 0.051 & - & - \\
\hline TSM/ŞU-ŞB & 0.74 & 0.033 & 0.90 & 0.0008 & 0.385 & 0.051 & 0.59 & 0.0032 \\
\hline
\end{tabular}

\section{Sonuçlar}

$\mathrm{Bu}$ çalışma sonunda bir su dağıtım şebekesindeki GGSO tahminlerinde, Kriging yönteminin kullanılmasının, YSA'ya göre oldukça avantajlı olduğu bir kez daha görülmüştür. Kriging yöntemi ile GGSO tahminlerinde şebeke yaşı model performansları şebeke basıncına göre çok daha iyidir. Ancak şebeke yaşının doğru şekilde tanımlanmasında güçlüklerin söz konusu olduğu da bir gerçektir. Önemli diğer bir sonuçta YSA ve Kriging yöntemlerine ilişkin sonuçların yorumlanmasında ortaya çıkmaktadır. YSA model yapısı kapalı bir sistem olup, sonuçlar üzerinden yorumlar geliştirilmesi kolay değildir. Buna karşın Kriging yönteminde elde edilen model haritaları üzerinden yorum ve değerlendirmelerde bulunulması söz konusudur. Kriging model haritaları yardımıyla değişkenler arasındaki mantık ilişkilerinin şekil bilgisine dayanarak sorgulanması ve uzmanların konuya ilişkin tecrübe kazanabilmeleri mümkündür. GGSO'nun oldukça yüksek olduğu dağıtım şebekeleri içinde, Kriging yöntemi ile elde edilen modellerin performansları yüksek olup, kabul edilebilir tahminler ortaya konulmuştur.

\section{Çıkar çatışması}

Yazarlar çıkar çatışması olmadığını beyan etmektedir.

\section{Benzerlik oranı (iThenticate): \%6}

\section{Kaynaklar}

[1] R. Liemberger and A. Wyatt, Quantifying the global non-revenue water problem. Water Science and Technology: Water Supply, 19 (10), 831-837, 2019. https://doi.org/10.2166/ws.2018.129.

[2] IBNET, The international benchmarking networks. https://database.ibnet.org/Reports/Indicators/HeatMap ?itemId=27, Accessed 06 November 2020.
[3] AWWA, Best practice in water loss control: improved concepts for $21 \mathrm{st}$ century water management, American Water Works Association. https://www. awwa.org/Portals/0/AWWA/ETS/Resources/WLCFly erFinal.pdf?ver=2015-02-10-083650-287.

[4] IWA, Assessing Non-Revenue Water and its Components: A Practical Approach. The IWA water loss task force, Water 21, 2003.

[5] V. Kanakoudis and H. Muhammetoglu, Urban water pipe networks management towards non-revenue water reduction: Two case studies from Greece and Turkey. Clean-Soil, Air, Water 42 (7), 880-892, 2014. https://doi.org/10.1002/clen.201300138.

[6] F. Boztaş, Ö Özdemir, F. M. Durmuşçelebi and M. Firat, Analyzing the effect of the unreported leakages in service connections of water distribution networks on non-revenue water. International Journal of Environmental Science and Technology, 16 (8), 4393 4406, 2018. https://doi.org/10.1007/s13762-018-20850.

[7] M. Tabesh, A. Asadiyami Yekta, R. Burrows, An integrated model to evaluate losses in water distribution systems, Water Resources Management. 23 (3), 477-492, 2009. https://doi.org/10.1007/s112 69-008-9284-2.

[8] H. E. Mutikanga, S. K. Sharma, K. Vairavamoorthy, Multi-criteria decision analysis: A strategic planning tool for water loss management, Water Resources Management. 25, 3947-3969, 2011. https://doi.org/ 10.1007/s11269-011-9896-9.

[9] H. E. Mutikanga, S. K. Sharma, K. Vairavamoorthy, Assessment of apparent losses in urban water systems. Water and Environment Journal, 25 (3), 327-335, 2011. https://doi.org/10.1111/j.1747-6593.2010 00 225.x.

[10] C. van den Berg, Drivers of non-revenue water: A cross-national analysis. Utilities Policy, 36, 71-78, 2015. https://doi.org/ 10.1016/j.jup.2015.07.005.

[11] S. H. Zyoud, L. G. Kaufmann, H. Shaheen, S. Samhan and D. Fuchs-Hanusch, A framework for water loss management in developing countries under fuzzy environment: Integration of Fuzzy AHP with Fuzzy TOPSIS. Expert Systems with Applications, 61, 86105, 2016. https://doi.org/10.1016/j.eswa.2016.05.016.

[12] M. Tabesh, A. Roozbahani, B. Roghani, N. R. Faghihi and R. Heydarzadeh, Risk Assessment of factors influencing non-revenue water using bayesian networks and fuzzy logic. Water Resources Management, 32 (11), 3647-3670, 2018. https:// doi.org/10.1007/s11269-018-2011-8.

[13] K. Gonelas and V. Kanakoudis, Reaching economic leakage level through pressure management. Water Science and Technology: Water Supply, (16), 3, 756765, 2016. https://doi.org/10.2166/ws.2015.181.

[14] G. Güngör-Demirci, J. Lee, J. Keck, R. Guzzetta and P. Yang, Determinants of non-revenue water for a water utility in California. Journal of Water Supply: Research 
and Technology - AQUA, vol. 67 (3), 270-278, 2018. https://doi.org/10.2166/aqua.2018.152.

[15] D. Jang and G. Choi, Estimation of non-revenue water ratio using MRA and ANN in water distribution networks. Water, (10), 1, 1-13, 2018. https://doi.org/ 10.3390/w10010002.

[16] D. Jang and G. Choi, Estimation of non-revenue water ratio for sustainable management using artificial neural network and Z-score in Incheon, Republic of Korea. Sustainability, (9), 11, 1933, 2017. https://doi.org/ 10.3390/su9111933.

[17] E. Şişman and B. Kizilöz, Artificial neural network system analysis and Kriging methodology for estimation of non-revenue water ratio. Water Supply,
(20), 5, 1871-1883, 2020. https://doi.org/ 10.2166/ ws.2020.095.

[18] İSU, Kocaeli Su ve Kanalizasyon İdaresi Genel Müdürlüğü, Yıllık faaliyet raporları, 2019.

[19] B. Kizilöz, E. Çevik ve B. Aydoğan, Estimation of scour around submarine pipelines with Artificial Neural Network. Applied Ocean Research, (51), 241251, 2015. https://doi.org/10.1016/j.apor.2015.04.006.

[20] C. M. Yeşilkanat, Y. Kobya, H. Taşkin and U. Çevik, Dose rate estimates and spatial interpolation maps of outdoor gamma dose rate with geostatistical methods; A case study from Artvin, Turkey. Journal of Environmental Radioactivity, (150),132-144, 2015. https://doi.org/10.1016/j.jenvrad.2015.08.011. 